\title{
Rick Factors Associated with Aspiration in Patients with Head and Neck Cancer
}

\author{
Soo Jin Jung, M.D., Deog Young Kim, M.D., Ph.D., So Young Joo, M.D.
}

Department and Research Institute of Rehabilitation Medicine, Yonsei University College of Medicine, Seoul 120-752, Korea

Objective To determine the major risk factors and abnormal videofluoroscopic swallowing study (VFSS) findings associated with aspiration in patients with head and neck cancer (HNC).

Method Risk factors associated with aspiration were investigated retrospectively in 241 patients with HNC using medical records and pre-recorded VFSS. Age, gender, lesion location and stage, treatment factors, and swallowing stage abnormalities were included.

Results Aspiration occurred in $50.2 \%$ of patients. A univariate analysis revealed that advanced age, increased duration from disease onset to VFSS, higher tumor stage, increased lymph node stage, increased American Joint Committee on Cancer (AJCC) stage, operation history, chemotherapy history, and radiotherapy history were significantly associated with aspiration $(\mathrm{p}<0.05)$. Among them, advanced age, increase AJCC stage, operation history, and chemotherapy history were significantly associated with aspiration in the multivariate analysis $(p<0.05)$. Delayed swallowing reflex and reduced elevation of the larynx were significantly associated with aspiration in the multivariate analysis $(\mathrm{p}<0.05)$.

Conclusion The major risk factors associated with aspiration in patients with HNC were advanced age, higher AJCC stage, operation history, and chemotherapy history. A VFSS to evaluate aspiration is needed in patients with NHC who have these risk factors. Delayed swallowing reflex and reduced elevation of the larynx were major abnormal findings associated with aspiration. Dysphagia rehabilitation should focus on these results.

Key Words Aspiration, Head and neck cancer, Videofluoroscopic swallowing study (VFSS)

Received August 16, 2011; Accepted October 5, 2011

Corresponding author: Deog Young Kim

Department and Research Institute of Rehabilitation Medicine, Yonsei University College of Medicine, 134, Shinchon-dong, Seodaemun-gu, Seoul 120-752, Korea

Tel: +82-2-2228-3710, Fax: +82-2-363-2795, E-mail: kimdy@yuhs.ac (c) This is an open-access article distributed under the terms of the Creative Commons Attribution Non-Commercial License (http:// creativecommons.org/licenses/by-nc/3.0) which permits unrestricted noncommercial use, distribution, and reproduction in any medium, provided the original work is properly cited.

Copyright $\odot 2011$ by Korean Academy of Rehabilitation Medicine

\section{INTRODUCTION}

Head and neck cancer (HNC) includes tumors extending into the oral cavity, the pharynx, and the larynx. It arises in anatomical regions related to the swallowing function, but the incidence rate of aspiration varies from $36-94 \%$ in patients with HNC. ${ }^{1-6}$ Additionally, the incidence rate of a silent aspiration, caused by the decline in cough reflex, is $22-67 \% .^{7-9}$ Nevertheless, many cases occur in which an aspiration passes unnoticed in clinical practice. Aspiration may not only occur due to cancer but also due to surgery, radiotherapy, or chemotherapy. ${ }^{10}$ Aspiration may cause pneumonia and malnutrition in patients with 
HNC and, thus, may affect prognosis, ${ }^{6,11}$ particularly in patients whose immune system is impaired by cancer treatment. Even mild aspiration may lead to sepsis or respiratory failure. ${ }^{1}$

Accordingly, it is important to screen patients with HNC, who have a high risk for aspiration, to conduct systematic examinations of the aspiration and swallowing processes, and to undergo dysphagia rehabilitation. Some studies have attempted to identify risk factors for aspiration in patients with HNC, ${ }^{3,12-14}$ whereas very few systematic and large scale studies in patients with HNC have been conducted in Korea. If high-risk patients are screened to identify risk factors for aspiration, aspiration can be more carefully monitored in clinical practice, which would positively influence the prognosis. Additionally, the pathogenetic mechanism of aspiration can be explained if the factors responsible for aspiration can be identified on a videofluoroscopic swallowing study (VFSS), which will be helpful for dysphagia rehabilitation.

This study identified risk factors for aspiration in patients with HNC and conducted a VFSS for the swallowing process. We enrolled 242 patients who were diagnosed with HNC and who underwent VFSS at Yonsei University Medical Center. Medical records were retrospectively analyzed for demographic information, HNC characteristics, and a history of cancer treatment.

\section{MATERIALS AND METHODS}

\section{Subjects}

This study was conducted on 221 of 242 patients who were diagnosed with HNC and who underwent VFSS between April 2007 and December 2010 at Yonsei University Medical Center. Twenty-one patients were excluded due to inadequate imaging studies, histological findings, tumor locations, and tumor stages (11), or if the medical treatment history could not be traced (3) and where strokes, head and neck trauma, and degenerative neurologic diseases occurred in the past (7). The mean age of the patients was 57.7 years. There were 173 men (78.3\%) and $48(21.7 \%)$ women. They had VFSS an average of 8.88 months after being diagnosed with HNC. Dysphagia occurred in 155 (70.1\%) patients. Tumors were located in the oropharynx $(74,33.5 \%)$, larynx (15, $6.8 \%)$, hypopharynx $(18,8.1 \%)$, oral cavity $(98,44.3 \%)$, nasopharynx $(10,4.5 \%)$, and salivary glands $(6,2.7 \%)$.
Table 1. General Subject Characteristics

\begin{tabular}{|c|c|}
\hline Characteristics & Value $(n, \%)$ \\
\hline \multicolumn{2}{|l|}{ Sex } \\
\hline Male & $173(78.3)$ \\
\hline Female & $48(21.7)$ \\
\hline \multicolumn{2}{|l|}{ Age (year) } \\
\hline Mean & $57.7 \pm 13.1$ \\
\hline Range & $21-79$ \\
\hline Time interval from onset (months) & $8.8 \pm 15.6$ \\
\hline$<3$ & $108(48.9)$ \\
\hline $3-6$ & $23(10.4)$ \\
\hline $6-12$ & $33(14.9)$ \\
\hline$\geq 12$ & $57(25.8)$ \\
\hline \multicolumn{2}{|l|}{ Lesion } \\
\hline Oropharynx & $74(33.5)$ \\
\hline Larynx & $15(6.8)$ \\
\hline Hypopharynx & $18(8.1)$ \\
\hline Oral cavity & $98(44.3)$ \\
\hline Nasopharynx & $10(4.5)$ \\
\hline Salivary gland & $6(2.7)$ \\
\hline \multicolumn{2}{|l|}{ Tumor stage } \\
\hline $\mathrm{T} 1$ & $70(31.6)$ \\
\hline $\mathrm{T} 2$ & $78(35.2)$ \\
\hline T3 & $31(14.0)$ \\
\hline $\mathrm{T} 4$ & $42(19.0)$ \\
\hline \multicolumn{2}{|l|}{ Nodal stage } \\
\hline No & $80(36.2)$ \\
\hline N1 & $39(17.6)$ \\
\hline N2 & $102(46.2)$ \\
\hline \multicolumn{2}{|l|}{ AJCC stage } \\
\hline I & $42(19.0)$ \\
\hline II & $53(24.0)$ \\
\hline III & $78(35.3)$ \\
\hline IVa & $48(21.7)$ \\
\hline \multicolumn{2}{|l|}{ Treatment } \\
\hline None & $96(43.4)$ \\
\hline $\mathrm{Op}$ & $80(36.2)$ \\
\hline Op+CTx or RTx & $8(3.7)$ \\
\hline $\mathrm{Op}+\mathrm{CTx}+\mathrm{RTx}$ & $22(10.0)$ \\
\hline Others & $15(6.7)$ \\
\hline \multicolumn{2}{|l|}{ Swallowing performance scale } \\
\hline 1 & $66(29.9)$ \\
\hline 2 & $82(37.1)$ \\
\hline 3 & $30(13.5)$ \\
\hline 4 & $18(8.1)$ \\
\hline 5 & $6(2.7)$ \\
\hline 6 & $4(1.8)$ \\
\hline 7 & $15(6.7)$ \\
\hline
\end{tabular}

Op: Operation, CTx: Chemotherapy, RTx: Radiotherapy 
Regarding classification of the American Joint Committee on Cancer (AJCC) stage, 42 (19.0\%), 53 (24.0\%), 78 $(35.3 \%)$, and $48(21.7 \%)$ were classified as stage I, stage II, stage III, and stage IVa, respectively. Ninety-six (43.4\%) patients did not start treatment, $80(36.2 \%)$ underwent only an operation, eight (3.7\%) underwent both an operation and chemotherapy or radiotherapy, and 22 (10.0\%) underwent an operation and chemoradiotherapy.

In relation to Karnell and MacCracken's swallowing performance scale (SPS), ${ }^{15} 66$ (29.9\%), 82 (37.1\%), 30 (13.5\%), 18 (8.1\%), 6 (2.7\%), 4 (1.8\%) and 15 (6.7\%) were classified as grades 1-7 in the order named (Table 1).

\section{Methods}

Data collected from medical records and the VFSS were analyzed retrospectively. Patient information such as age and gender, tumor locations, tumor sizes, lymph node stages, AJCC stages, ${ }^{16}$ SPS,${ }^{15}$ and a history of operations, chemotherapy, or radiotherapy were analyzed at the time of VFSS. To perform VFSS, 5 or $15 \mathrm{cc}$ of $12 \%$ or $6 \%$ semisolid or liquid containing gastrograffin were used in each patient. VFSS was performed on a lateral view using radiologic fluoroscopy (Winscope, Toshiba, Japan), and images were recorded in real time. Abnormalities in the swallowing process were evaluated in detail using the real-time recorded images. Patients with aspiration were sorted out, and aspiration was defined as bolus passing through the vocal cords once. ${ }^{17}$

Age, gender, duration from onset to examination, tumor location, tumor size, lymph node stage, AJCC stage, and cancer treatment modalities were regarded as risk factors for aspiration. Patients $<65$ years were distinguished from those aged $\geq 65$ years. ${ }^{18}$ The duration from onset to examination was defined from the day when the HNC diagnosis was given until the day when VFSS was performed. The duration from onset to examination was classified into four periods based on Petterson et al. ${ }^{19}(<3$ months, 3 months, longer than 3 months but less than 6 months, greater than 6 months but less than 12 months, and $\geq 12$ months). Patients with HNC that extended into the larynx or pharynx (laryngeal, oropharyngeal or hypopharyngeal cancers) were distinguished from those with HNC extending into the oral cavity (oropharyngeal, oral cavity, or salivary gland cancers).$^{20} \mathrm{~T} 1$ and $\mathrm{T} 2$ tumors were distinguished from T3 and T4 tumors. N0 stage lymph nodes were distinguished from $\mathrm{N} 1$ and $\mathrm{N} 2$ nodes.
AJCC stages I and II were distinguished from stages III and IV.

The chi-square test was performed to confirm whether the foregoing factors influenced aspiration. Forward stepwise multivariate logistic regression analyses were conducted on statistically significant factors, independent risk factors were evaluated, and odd ratios were calculated. The main factor was identified in the same way as the foregoing factors for aspiration-related abnormal findings detected on the VFSS. All statistical data were analyzed with SPSS version 17.0 for Windows (SPSS Inc., Chicago, USA). A p-value $<0.05$ was considered significant.

\section{RESULTS}

\section{VFSS results}

Aspiration was detected in 111 (50.2\%) of 221 patients. Oral phase dysphagia and pharyngeal phase dysphagia were detected in $40(18.1 \%)$ and $154(69.7 \%)$ respectively, one $(0.4 \%)$ of whom showed dysphagia only at the oral phase. Dysphagia occurred only at the pharyngeal phase in $115(52.0 \%)$ patients. Dysphagia occurred not only at the oral phase but also at the pharyngeal phase in 39 (17.6\%). Thus, pharyngeal dysphagia comprised a higher proportion than that of oral dysphagia. Inadequate tongue movement was detected in $25(11.3 \%)$ patients with oral phase dysphagia and comprised the highest proportion. Patients with a vallecular remnant comprised

Table 2. Videofluoroscopic Swallowing Study Findings in Patients with Head and Neck Cancer

\begin{tabular}{lc}
\hline \multicolumn{1}{c}{ Findings } & Value (n, \%) \\
\hline Oral dysphagia & $40(18.1)$ \\
Inadequate labial closure & $1(0.5)$ \\
Inadequate tongue movement & $25(11.3)$ \\
Pharyngeal dysphagia & $154(69.7)$ \\
Delayed swallowing reflex & $95(43.0)$ \\
Inadequate closure of velopharyngeal port & $15(6.8)$ \\
Inadequate pharyngeal peristalsis & $97(43.9)$ \\
Reduced laryngeal elevation & $45(20.4)$ \\
Vallecular remnant & $119(53.8)$ \\
Cricopharyngeal dysfunction & $27(12.2)$ \\
Aspiration & \\
None & $110(49.8)$ \\
Present & $111(50.2)$ \\
\hline
\end{tabular}


the highest proportion of patients with pharyngeal phase dysphagia $(119,53.8 \%)$, followed by inadequate pharyngeal peristalsis $(97,43.9 \%)$, delayed swallowing reflex $(95,43.0 \%)$, and reduced laryngeal elevation $(45$, $20.4 \%$ ) (Table 2).
Risk factors associated with aspiration in HNC

Aspiration occurred at a significantly higher incidence in patients aged $\geq 65$ years than in patients aged $<65$ years $(\mathrm{p}<0.05)$. However, no inter-gender difference was observed. Aspiration showed a higher incidence during the period from onset to examination $(\mathrm{p}<0.05)$.

Aspiration occurred at a significantly higher incidence

Table 3. Incidence of Aspiration and the Univariate and Multivariate Analyses of Patient Factors

\begin{tabular}{|c|c|c|c|c|}
\hline Variable & $\begin{array}{c}\text { Composite } \\
\text { aspiration }(n, \%)\end{array}$ & $\mathbf{p}$ & $\begin{array}{c}\text { Multivariate OR } \\
(95 \% \mathrm{CI})\end{array}$ & $\mathbf{p}$ \\
\hline Gender & & 0.180 & & \\
\hline Male & $91(52.6)$ & & & \\
\hline Female & $20(41.6)$ & & & \\
\hline Age (y) & & $0.001^{*}$ & & $0.005^{*}$ \\
\hline$<65$ & $60(42.2)$ & & 1 (referent) & \\
\hline$\geq 65$ & $51(64.5)$ & & $2.499(1.319-4.736)$ & \\
\hline \multicolumn{5}{|c|}{$\begin{array}{l}\text { Duration from onset to examination } \\
\text { (months) }\end{array}$} \\
\hline$<3$ & $32(29.6)$ & $0.000^{*}$ & & \\
\hline $3-6$ & $12(52.1)$ & & & \\
\hline $6-12$ & $22(66.6)$ & & & \\
\hline$\geq 12$ & $45(78.9)$ & & & \\
\hline Primary site & & 0.248 & & \\
\hline OPx, OC, SG & $86(48.3)$ & & & \\
\hline Lx, HPx, NPx & $25(58.1)$ & & & \\
\hline T stage & & $0.003^{*}$ & & \\
\hline $\mathrm{T} 1-\mathrm{T} 2$ & $64(43.2)$ & & & \\
\hline T3-T4 & $47(64.4)$ & & & \\
\hline $\mathrm{N}$ stage & & $0.022^{*}$ & & \\
\hline No & $32(40.0)$ & & & \\
\hline N1-2 & $79(56.0)$ & & & \\
\hline AJCC stage & & $0.000^{*}$ & & $0.007^{*}$ \\
\hline Stage I-II & 33 (33.7) & & 1 (referent) & \\
\hline Stage III-IV & 78 (61.9) & & $2.350(1.258-4.390)$ & \\
\hline Operation & & $0.000^{*}$ & & $0.002^{*}$ \\
\hline No & $41(36.9)$ & & 1 (referent) & \\
\hline Yes & $70(63.6)$ & & $2.617(1.441-4.752)$ & \\
\hline Chemotherapy & & $0.000^{*}$ & & $0.002^{*}$ \\
\hline No & $76(42.2)$ & & 1 (referent) & \\
\hline Yes & $35(85.4)$ & & $4.743(1.802-12.487)$ & \\
\hline Radiotherapy & & $0.000^{*}$ & & \\
\hline No & $79(43.2)$ & & & \\
\hline Yes & $32(84.2)$ & & & \\
\hline
\end{tabular}

Lx: Larynx, HPx: Hypopharynx, OPx: Oropharynx, OC:Oral cavity, NPx: Nasopharynx, SG: Salivary gland ${ }^{*} \mathrm{p}<0.05$ 
in tumors classified as T3 or T4 than in those classified as T1 or T2 ( $\mathrm{p}<0.05)$. Additionally, the incidence was significantly higher in tumors extending into the lymph nodes $(\mathrm{p}<0.05)$. Aspiration incidence was higher in patients classified as AJCC stage III or IV than in those classified as stages I or II $(\mathrm{p}<0.05)$. Tumors were located slightly more frequently in the larynx or pharynx than in the oral cavity, but the difference was not significant. Aspiration showed a statistically significant higher incidence in patients who underwent an operation, chemotherapy, or radiotherapy than in those who did not start treatment $(\mathrm{p}<0.05)$.

Multivariate logistic regression analyses revealed that patients aged $\geq 65$ years, who were classified as AJCC stage III or IV, who underwent operation, and who underwent chemotherapy were the high-risk group $(\mathrm{p}<0.05)$. The incidence of aspiration was 2.5 times higher in patients aged $\geq 65$ years than in those aged $<65$ years (odds ratio [OR], 2.499 (95\% confidence interval [CI], 1.319-4.736) and was 2.4 times higher in patients classified as AJCC stage III or IV than in those classified as stage I or II (OR, 2.350; 95\% CI, 1.258-4.390). The incidence of aspiration was 2.6 times higher in patients who underwent an operation than in those who did not (OR, 2.6; 95\% CI, 1.4-4.8). In particular, the incidence of aspiration was 4.7 times higher in patients who underwent chemotherapy than in those who did not (OR, 2.617; 95\% CI,1.441-4.752) (Table 3).

Table 4. Incidence of Aspiration and the Univariate and Multivariate Analyses of Videofluroscopic Swallowing Study Findings

\begin{tabular}{|c|c|c|c|c|}
\hline Variable & $\begin{array}{c}\text { Composite aspiration } \\
(\mathrm{n}, \%)\end{array}$ & p & $\begin{array}{c}\text { Multivariate OR } \\
(95 \% \mathrm{CI})\end{array}$ & p \\
\hline Labial closure & & 0.318 & & \\
\hline Intact & $110(50.0)$ & & & \\
\hline Inadequate & $1(100.0)$ & & & \\
\hline Tongue movement & & $0.000^{*}$ & & \\
\hline Intact & $88(44.9)$ & & & \\
\hline Inadequate & $23(92.0)$ & & & \\
\hline Swallowing reflex & & $0.000^{*}$ & & $0.000^{*}$ \\
\hline Normal & $30(23.8)$ & & 1 (referent) & \\
\hline Delayed & $81(85.2)$ & & $14.462(7.036-29.726)$ & \\
\hline Closure of velopharyngeal port & & $0.000^{*}$ & & \\
\hline Intact & $99(48.0)$ & & & \\
\hline Inadequate & $12(80.0)$ & & & \\
\hline Pharyngeal peristalsis & & $0.000^{*}$ & & \\
\hline Intact & $37(78.2)$ & & & \\
\hline Inadequate & $74(76.2)$ & & & \\
\hline Elevation of larynx & & $0.000^{*}$ & & $0.031^{*}$ \\
\hline Normal & $73(41.4)$ & & 1 (referent) & \\
\hline Reduced & $38(84.4)$ & & $3.038(1.110-8.317)$ & \\
\hline Cricopharyngeal dysfunction & & $0.025^{*}$ & & \\
\hline No & $92(47.4)$ & & & \\
\hline Yes & $19(70.3)$ & & & \\
\hline Vallecular remnant & & $0.000^{*}$ & & \\
\hline None & $28(27.4)$ & & & \\
\hline Present & $83(69.7)$ & & & \\
\hline
\end{tabular}

$* \mathrm{p}<0.05$ 
Abnormal swallowing findings associated with aspiration on VFSS

Inadequate tongue movement was related to aspiration during the oral phase. At the pharyngeal phase, factors associated with aspiration were decreased pharyngeal reflex, inadequate closure of the velopharyngeal port, inadequate pharyngeal peristalsis, reduced laryngeal elevation, cricopharyngeal dysfunction, and the presence of a vallecular remnant $(p<0.05)$. The multivariate logistic regression analysis revealed that the incidence of aspiration was 14.5 times higher in patients with a decreased pharyngeal reflex than that in patients without a decreased pharyngeal reflex (OR, 14.5; 95\% CI, 7.0-29.7) and was 3.0 times higher in those with reduced laryngeal elevation than in those without (OR, 3.038; 95\% CI, 1.1108.317) $(\mathrm{p}<0.05)$ (Table 4).

\section{DISCUSSION}

Aspiration occurred in $50.2 \%$ of patients with HNC, which agreed with that of previous studies (36-94\%). ${ }^{1-6}$

Aspiration in patients with HNC may be caused by various factors, including abnormal motility of swallowing-related structures, ${ }^{21}$ resection of a tumor, structural muscular, bony, or cartilage damage caused by surgery or by scar tissue formation from radiotherapy, or by the abnormal motility of the oral, pharyngeal, and laryngeal muscles caused by cell apoptosis resulting from chemotherapy. ${ }^{22,23}$ In this study, VFSS was performed on comparatively more patients with HNC (221) than those used in previous studies, which made it possible to analyze the characteristics of patients and HNC as well as to identify major risk factors for aspiration.

Gender was not related to aspiration, but age was significantly related to aspiration incidence. Previous studies showed different results regarding the correlation between age and aspiration. Caudell et al. ${ }^{19}$ reported that advanced age was an important factor predicting dysphagia in patients with HNC who underwent treatment. Advanced age was related to the incidence of aspiration in a study conducted on healthy subjects. ${ }^{23,24}$ The correlation between age and aspiration has not been clarified yet. However, the incidence of aspiration may increase not only with natural aging but by comorbidities that can affect the swallowing function.

Aspiration showed a significantly higher incidence from onset to examination. But significant differences were not observed when other variables were controlled in the multivariate logistic regression analysis. According to the report of Logemann et al. ${ }^{25}$ who performed VFSS on patients 3 and 12 months after they underwent radiotherapy or chemoradiotherapy, dysphagia and aspiration showed significantly higher incidences before and 3 months after treatments. But, significant changes were not observed 12 months after treatments. In a study by Petterson et al., ${ }^{20}$ the functional endoscopic swallowing study and the $100 \mathrm{cc}$ water swallowing test were performed on patients who underwent radiotherapy or chemoradiotherapy. The incidence of aspiration increased at 3, 6, and 12 months after the operations, respectively, rather than before the operations. However, no inter-period differences were reported. In this study, the incidence of aspiration increased in proportion to the duration from onset to examination. The incidence may not have been affected by duration itself but by increasing the proportion of patients who underwent operations, chemotherapy, or radiotherapy with time. These results were similar to those of previous studies.

Interestingly, tumor location was not a risk factor in this study. In contrast, Stenson et al. ${ }^{13}$ reported that the incidence rate of aspiration reaches 30,67 , and $80 \%$ in patients with oral, laryngeal, and pharyngeal HNCs respectively, whereas Starmer et al. ${ }^{18}$ reported that HNC extending into the larynx or the hypopharynx is a principal risk factor for aspiration. Campbell et al. ${ }^{26}$ reported that tumor location has no relation to aspiration in subjects who survived for 5 years or longer after undergoing treatment. Eischbruch et al. ${ }^{6}$ reported that though swallowing-related structures were normal, radiotherapy and chemotherapy affects movement of the oral cavity and laryngopharyngeal musculature and, thus, causes aspiration. Chapuy et al. ${ }^{27}$ reported that tumor location does not affect the risk of gastrostomy in patients who underwent radiotherapy, chemotherapy, or an operation. Taken together, aspiration in patients with HNC is affected by their history of radiotherapy, chemotherapy, or an operation rather than by tumor location.

In this study, tumor size, lymph node stage and AJCC stage were associated with aspiration, and AJCC stage was the principal predictive factor. Stenson et al. ${ }^{13}$ reported that AJCC stage has no relationship to the in- 
cidence of aspiration in patients with HNC. In contrast, Nguyen et al., ${ }^{28}$ who conducted a study on patients with oropharyngeal cancer that underwent radiotherapy or chemotherapy, reported that the risk of aspiration was higher in patients with tumors classified as $\mathrm{T} 3$ or $\mathrm{T} 4$ than in those classified as $\mathrm{T} 1$ or T2. This result was consistent with the report of Chapuy et al. ${ }^{27}$ who found that tumor locations do not heighten the risk for gastrotomy in patients who undergo radiotherapy, chemotherapy, or an operation, suggesting that higher AJCC stage is relevant to the occurrence of aspiration and, at the same time, needs more aggressive therapies.

The incidence of aspiration was significantly higher in patients with HNC who underwent an operation than in those who did not, and operation history was an independent predictive factor. Previous studies have indicated that the incidence rate of aspiration is 10 $37 \%^{29}$ and $50-67 \%^{30}$ in patients who undergo a total glossectomy and supraglottic laryngectomy, respectively. Such operations remove not only tumors but normal muscles and bones for the purpose of marginal security, and, as a result, swallowing-related organs malfunction. Despite that the flap operation was performed, it resulted in restricted motion. Dysphagia may occur after surgery. ${ }^{31}$ According to the report by Lango et al., ${ }^{32}$ tissue fibrosis and edema were aggravated in patients who underwent an operation in addition to radiotherapy or chemotherapy, which remarkably heightens the possibility of tube feeding. Thus, surgery may be an additional risk factor for aspiration.

Chemotherapy is a principal predictive factor of aspiration. Nguyen et al. ${ }^{33}$ reported that the incidence rate of aspiration increases from $17 \%$ to $59 \%$ after chemotherapy. Odynophagia caused by mucositis, glossitis, fibrosis, and lymphedema resulting from apoptosis caused by cytotoxic anticancer drugs affects aspiration. ${ }^{34}$

Radiotherapy is related with aspiration. Pauloski and Logemann ${ }^{35}$ reported that radiotherapy heightens the risk of aspiration by $35 \%$ and increases vallecular remnants. This occurs because radiotherapy causes fibrosis and decreases muscle activity of swallowing-related structures. ${ }^{5,34}$ However, we found that radiotherapy was relevant to aspiration but was not a principal predictive factor. In contrast, chemotherapy was a principal risk factor. These results agree with the report of Nguyen et al. ${ }^{33}$ that dysphagia develops more often in patients who undergo both chemotherapy and radiotherapy than in those who undergo radiotherapy alone. Caudell et al. ${ }^{19}$ reported that chemotherapy is the most important risk factor causing severe dysphagia in patients who undergo radiotherapy. It is necessary to compare radiotherapy and chemotherapy separately with a sufficient number of patients. Actually, there are few cases in which chemotherapy or radiotherapy is independently performed. Similarly, in this study, only a few patients underwent radiotherapy or chemotherapy alone.

Eisbruch et al. ${ }^{6}$ reported reduced base-of-tongue retraction (41\%), delayed swallowing reflex (36\%), the presence of a vallecular remnant (23\%), and reduced pharyngeal and laryngeal elevation (18\%) in patients with HNC before therapy. After chemoradiotherapy, reduced base-of-tongue retraction (85\%), delayed swallowing reflex (62\%), presence of a vallecular remnant $(77 \%)$, and reduced pharyngeal and laryngeal elevation (46\%) showed a higher prevalence. In addition, velopharyngeal port dysfunction (15\%) and incomplete cricopharyngeal relaxation $(46 \%)$ were newly observed after treatments. Wu et al.$^{36}$ reported that oropharyngeal dysfunction (75\%), delayed swallowing reflex (87.1\%), presence of a vallecular remnant (93.5\%), and incomplete pharyngeal contraction (82.8\%) occurred at higher frequencies in patients with nasopharyngeal cancer who underwent radiotherapy, and that they had a relationship to aspiration. Galli et al. ${ }^{37}$ reported that pharyngeal residue occurred more frequently in patients who underwent an operation than in those with neurological dysphagia. This study showed similar results, and inadequate tongue movement, delayed swallowing reflex, inadequate closure of the velopharyngeal port, inadequate pharyngeal peristalsis, reduced laryngeal elevation, cricopharyngeal dysfunction, and presence of a vallecular remnant were related with aspiration. In particular, delayed swallowing reflex and reduced laryngeal elevation were principal risk factors, which was not consistent with the report of $\mathrm{Wu}$ et al. ${ }^{8}$ who found that inadequate pharyngeal peristalsis and cricopharyngeal dysfunction are related to aspiration in patients with nasopharyngeal cancer who underwent radiotherapy. The reason might be that endoscopy cannot evaluate laryngeal elevation. Reduced laryngeal elevation was related to the occurrence of aspiration in the study by Logemann and Bytell. ${ }^{38}$

The limitation of this study was that the results were 
based on a retrospective analyses of medical records, not bedside or clinical demonstrations. Thus, influential factors may not have been controlled. This study was not conducted on all the patients with HNC in this hospital but on patients referred from other departments to the department of rehabilitation medicine for VFSS, which may have caused some biases. Moreover, the statistical analysis was not as accurate due to the small number of patients who underwent chemotherapy or radiotherapy alone. Additional limitations may have occurred due to treatment modalities that varied depending on tumor stage. Accordingly, a large-scale prospective study should be conducted on patients with HNC.

\section{CONCLUSION}

Advanced age, higher tumor stage, and a history of an operation and chemotherapy were principal risk factors for aspiration in patients with HNC. Thus, precise examinations, including VFSS, should be performed on patients with HNC. The VFSS results showed that the delayed swallowing reflex and reduced laryngeal elevation might be risk factors for aspiration, which suggests that dysphagia rehabilitation should be conducted based on such characteristics.

\section{REFERENCES}

1. Nguyen NP, Frank C, Moltz CC, Vos P, Smith HJ, Bhamidipati PV, Karlsson U, Nguyen PD, Alfieri A, Nguyen LM, et al. Aspiration rate following chemoradiation for head and neck cancer: an underreported occurrence. Radiother Oncol 2006; 80: 302-306

2. Nguyen NP, Moltz CC, Frank C, Vos P, Smith HJ, Karlsson U, Dutta S, Midyett FA, Barloon J, Sallah S. Dysphagia following chemoradiation for locally advanced head and neck cancer. Ann Oncol 2004; 15: 383-388

3. Kotz T, Costello R, Li Y, Posner MR. Swallowing dysfunction after chemoradiation for advanced squamous cell carcinoma of the head and neck. Head Neck 2004; 26: 365-372

4. Carrara-de Angelis E, Feher O, Barros AP, Nishimoto IN, Kowalski LP. Voice and swallowing in patients enrolled in a larynx preservation trial. Arch Otolaryngol Head Neck Surg 2003;129: 733-738
5. Steiniger JR, Parnes SM, Gardner GM. Morbidity of combined therapy for the treatment of supraglottic carcinoma: supraglottic laryngectomy and radiotherapy. Ann Otol Rhinol Laryngol 1997;106:151-158

6. Eisbruch A, Lyden T, Bradford CR, Dawson LA, Haxer MJ, Miller AE, Teknos TN, Chepeha DB, Hogikyan ND, Terrell JE, et al. Objective assessment of swallowing dysfunction and aspiration after radiation concurrent with chemotherapy for head-and-neck cancer. Int J Radiat Oncol Biol Phys 2002; 53: 23-28

7. Langerman A, Maccracken E, Kasza K, Haraf DJ, Vokes EE, Stenson KM. Aspiration in chemoradiated patients with head and neck cancer. Arch Otolaryngol Head Neck Surg 2007; 133: 1289-1295

8. Wu CH, Hsiao TY, Ko JY, Hsu MM. Dysphagia after radiotherapy: endoscopic examination of swallowing in patients with nasopharyngeal carcinoma. Ann Otol Rhinol Laryngol 2000; 109: 320-325

9. Hughes PJ, Scott PM, Kew J, Cheung DM, Leung SF, Ahuja AT, van Hasselt CA. Dysphagia in treated nasopharyngeal cancer. Head Neck 2000; 22: 393-397

10. Nguyen NP, Moltz CC, Frank C, Vos P, Smith HJ, Nguyen PD, Nguyen LM, Dutta S, Lemanski C, Sallah S. Impact of swallowing therapy on aspiration rate following treatment for locally advanced head and neck cancer. Oral Oncol 2007; 43: 352-357

11. Bernal-Sprekelsen M, Vilaseca-Gonzalez I, BlanchAlejandro JL. Predictive values for aspiration after endoscopic laser resections of malignant tumors of the hypopharynx and larynx. Head Neck 2004; 26: 103-110

12. Lazarus CL, Logemann JA, Pauloski BR, Colangelo LA, Kahrilas PJ, Mittal BB, Pierce M. Swallowing disorders in head and neck cancer patients treated with radiotherapy and adjuvant chemotherapy. Laryngoscope 1996; 106: 1157-1166

13. Stenson KM, MacCracken E, List M, Haraf DJ, Brockstein B, Weichselbaum R, Vokes EE. Swallowing function in patients with head and neck cancer prior to treatment. Arch Otolaryngol Head Neck Surg 2000; 126: 371-377

14. Humphreys B, Mathog R, Rosen R, Miller P, Muz J, Nelson R. Videofluoroscopic and scintigraphic analysis of dysphagia in the head and neck cancer patient. Laryngoscope 1987; 97: 25-32

15. Karnell M, Maccracken E, Moran W, Vokes E, Haraf D, 
Panje W. Swallowing function following multispecialty organ preservation treatment of advanced head and neck-cancer. Oncol Rep 1994; 1: 597-601

16. Edge SB. AJCC cancer staging manual (electronic resource), 7th ed, New York, Springer, 2010, 15-67

17. Pannunzio TG. Aspiration of oral feedings in patients with tracheostomies. AACN Clin Issues 1996; 7: 560569

18. Starmer H, Gourin C, Lua LL, Burkhead L. Pretreatment swallowing assessment in head and neck cancer patients. Laryngoscope 2011; 121: 1208-1211

19. Petterson JM, Hildreth A, McColl E, Carding PN, Hamilton D, Wilson JA. The clinical application of the $100 \mathrm{~mL}$ water swallow test in head and neck cancer. Oral Oncol 2011; 47: 180-184

20. Caudell JJ, Schaner PE, Meredith RF, Locher JL, Nabell LM, Carroll WR, Magnuson JS, Spencer SA, Bonner JA. Factors associated with long-term dysphagia after definitive radiotherapy for locally advanced headand-neck cancer. Int J Radiat Oncol Biol Phys 2009; 73: 410-415

21. Logemann JA, Rademaker AW, Pauloski BR, Pauloski BR, Lazarus CL, Mittal BB, Brockstein B, Maccracken E, Haraf DJ, Vokes EE, et al. Site of disease and treatment protocol as correlates of swallowing function in patients with head and neck cancer treated with chemoradiation. Head Neck 2006; 28: 64-73

22. Smith RV, Kotz T, Beitler JJ, Wadler S. Long-term swallowing problems after organ preservation therapy with concomitant radiation therapy and intravenous hydroxyurea: initial results. Arch Otolaryngol Head Neck Surg 2000; 126: 384-389

23. Kikawada M, Iwamoto T, Takasaki M. Aspiration and infection in the elderly: epidemiology, diagnosis and management. Drugs Aging 2005; 22: 115-130

24. Bloem BR, Lagaay AM, van Beek W, Haan J, Roos RA, Wintzen AR. Prevalence of subjective dysphagia in community residents aged over 87 . BMJ 1990; 300: 721-722

25. Logemann JA, Pauloski BR, Rademaker AW, Lazarus CL, Gaziano J, Stachowiak L, Newman L, MacCracken E, Santa D, Mittal B. Swallowing disorders in the first year after radiation and chemoradiation. Head Neck 2008; 30: 148-158

26. Campbell BH, Spinelli K, Marbella AM, Myers KB, Kuhn JC, Layde PM. Aspiration, weight loss, and quality of life in head and neck cancer survivors. Arch Otolaryngol Head Neck Surg 2004; 130: 1100-1103

27. Chapuy CI, Annino DJ, Snavely A, Li Y, Tishler RB, Norris CM, Haddad RI, Goguen LA. Swallowing function following postchemoradiotherapy neck dissection: review of findings and analysis of contributing factors. Otolaryngol Head Neck Surg 2011; 145: 428-434

28. Nguyen NP, Frank C, Moltz CC, Vos P, Smith HJ, Nguyen PD, Martinez T, Karlsson U, Dutta S, Lemanski $\mathrm{C}$, et al. Analysis of factors influencing aspiration risk following chemoradiation for oropharyngeal cancer. Br J Radiol 2009; 82: 675-680

29. Weber RS, Ohlms L, Bowman J, Jacob R, Goepfert H. Functional results after total or near total glossectomy with laryngeal preservation. Arch Otolaryngol Head Neck Surg 1991;117: 512-515

30. McConnel FM, Mendelsohn MS, Logemann JA. Manofluorography of deglutition after supraglottic laryngectomy. Head Neck Surg 1987; 9: 142-150

31. Kronenberger MB, Meyers AD. Dysphagia following head and neck cancer surgery. Dysphagia 1994; 9: 236-244

32. Lango MN, Egleston B, Ende K, Feigenberg S, D'Ambrosio DJ, Cohen RB, Ahmad S, Nicolaou N, Ridge JA. Impact of neck dissection on long-term feeding tube dependence in patients with head and neck cancer treated with primary radiation or chemoradiation. Head Neck 2010; 32: 341-347

33. Nguyen NP, Moltz CC, Frank C, Karlsson U, Nguyen PD, Vos P, Smith HJ, Dutta S, Nguyen LM, Lemanski C, et al. Dysphagia severity following chemoradiation and postoperative radiation for head and neck cancer. Eur J Radiol 2006; 59: 453-459

34. Gaziano JE. Evaluation and management of oropharyngeal dysphagia in head and neck cancer. Cancer control 2002; 9: 400-409

35. Pauloski BR, Logemann JA. Impact of tongue base and posterior pharyngeal wall biomechanics on pharyngeal clearance in irradiated postsurgical oral and oropharyngeal cancer patients. Head Neck 2000; 22: $120-131$

36. Wu CH, Hsiao TY, Ko JY, Hsu MM. Dysphagia after radiotherapy: endoscopic examination of swallowing in patients with nasopharyngeal carcinoma. Ann Otol Rhinol Laryngol 2000; 109: 320-325 
37. Galli J, Valenza V, D'Alatri L, Reale F, Gajate AS, Di Girolamo S, Paludetti G. Postoperative dysphagia versus Neurogenic dysphagia: scintigraphic assessment. Ann Otol Rhinol Laryngol 2003; 112: 20-28
38. Logemann JA, Bytell DE. Swallowing disorders in three types of head and neck surgical patients. Cancer 1979; 44: 1095-1105 